\title{
Method for Calculating the Capacity of Solar Power Plants and its Implementation in LabVIEW Environment
}

\author{
Grigory Okhotkin*, Alexander Serebryannikov, Valery Zakharov and Sergey Chumarov \\ I.N. Ulyanov Chuvash State University, Cheboksary, Russian Federation
}

\begin{abstract}
The paper presents the method for calculating the capacity of an autonomous solar power plant and its components. This method allows considering a load variation during the day as well as specifying the required capacity of the battery and excluding an unjustified overestimation of the power plant component capacities along with the increase in efficiency of the autonomous solar power plant. Formula for determining the required battery capacity of an autonomous solar power plant could be easily generalized for any number of changes in the load schedule steps. Virtual instruments (calculators) for calculating the capacity of an autonomous solar power plant and its components have been developed on the basis of this method in LabVIEW environment. These calculators may have a rather high visibility, ease of use and low memory requirements along with less computing time spent on calculations. The first calculator may allow recalculating capacities of loads on the power plant main supply bus as well as determining the energy consumption of loads per day. The second calculator may be used for determining the required capacity and number of batteries as well as the capacity of the charger, inverters, main supply bus and solar modules along with the solar power plant efficiency.
\end{abstract}

\section{Introduction}

Today, the electric energy production by solar power plants is used almost world-wide with a constant increase in solar cell application [1-4]. This is facilitated by many factors, and the main of them is the use of alternative (renewable) energy sources which have recently become increasingly important as well as a total absence of any moving parts, due to which their lifespan may be practically unlimited. Solar power plants are constantly being improved. Thus, they could be used today as additional electric power sources operating in conjunction with other sources or completely autonomously.

Solar power plants not connected to the industrial power grid, i.e. autonomous solar power plants (ASPPs) [5-12], are designed to supply electric energy to a small country house, summer cottage, sport ground, communication center, etc., i.e. to consumers located far from the power grid so that their power supply may usually involve high financial and labour costs.

ASPP may have a stabilized or non-stabilized output voltage. Functional diagrams of autonomous solar power plants may contain the following: solar batteries with the required capacity for converting sunlight into electric energy; DC/DC voltage pulse converters for reducing the floating voltage of solar modules and batteries to a stable voltage and charge of batteries that could be combined into the battery charge/discharge controller; batteries for accumulating and storing electric energy; autonomous voltage inverters (AVI) for converting DC to $220 \mathrm{~V}$ AC along with powering household appliances.

The development of ASPP may require determining the rated capacity of solar modules and their number as well as battery capacity, the capacity of inverter and charge/discharge controller. Here, the required data for calculating the solar power plant capacity may contain the following: location area; existing supply lines (if any); total house area; number of rooms; the use of electrical appliances; availability of heating and hot water supply; total maximum capacity of all electrical appliances; approximate operating time of each energy consumer.

Since these issues are not fully covered in the available literature, the development of the method for calculating the capacity of autonomous solar power plants and their components may gain urgency today.

The paper aims at the development of such method divided into several main stages for ease of presentation. As the result, a software tool for calculating the capacity of autonomous solar power plants and their components has been developed in LabVIEW environment.

\section{Methods}

We shall consider in greater detail the calculation method following the proposed stages. 


\subsection{Stage 1: Calculating the ASPP Output Capacity}

When developing an autonomous solar power plant, a list of all electric energy consumers specifying their energy consumption and voltage should be compiled (Table 1).

The alternating voltage consumers (No.1-No.4, Table 1) are connected to the ASPP main supply bus via individual AVIs, while the DC voltage consumers $N 1$ and $N 2$ (No. 7 and No. 8, Table 1) with voltages different from the rated voltage of the main bus - via buck and boost DC/DC pulse converters. The consumer (No. 5, Table 1) is connected "directly" to the main supply bus, while the consumer (No. 6, Table 1) is connected to an additional power bus, i.e. to a separate ASPP battery. The main supply bus is the bus to which an ASPP rechargeable battery is connected at night, either directly or via a boost DC/DC converter. In our case, a bus with DC voltage of $24 \mathrm{~V}$ corresponding to the ASPP battery voltage has been adopted as the main power bus.

If some loads having different types and values of supply voltages exist in the consumer list, then their capacities to ASPP main supply bus should be recalculated. Then, the capacities of individual loads on the main supply bus could be recalculated according to the following formula:

$$
P_{m b, i}=P_{\mathrm{c}, i} / \eta_{i}
$$

Here, $P_{c, i}$ is the $i$-th consumer capacity; $P_{m b, i}$ is the $i$ th consumer capacity recalculated for ASPP main bus; $\eta_{i}$ is the efficiency of the $i$-th AVI or the $i$-th DC/DC voltage converter for AC and DC consumers, respectively (in Table 1, the AVI and DC/DC converter efficiency is assumed equal to 0.8). If DC consumer is connected to the main supply bus "directly" or is powered from a separate battery with a voltage lower than the ASPP battery voltage (No. 6, Table 1), then the efficiency in the recalculation formula (1) is adopted equal to 1.

Then, the time of every electrical appliance operation during the day should be estimated to determine daily energy demand multiplying the appliance capacity by its operating time. The results should be recorded in a proper column of the table. This is the way the total energy consumption may be tabled.

A solar power plant can power a great number of electrical appliances, provided that their power consumption does not exceed the amount of electricity produced by ASPP. The list of electricity consumers contains loads running either permanently or nonpermanently (rarely and hardly ever). In turn, the loads running intermittently may be divided into loads running with a fixed and floating operating interval (e.g., a refrigerator - No. 3, Table 1). Neglecting these factors could result in an unjustified overestimation of the output capacity as well as an increase in ASPP cost. Therefore, the ASPP output capacity should be determined correctly.

The schedule of the load variation per day (i.e. the dependence of the total load capacity of the consumers operating at the moment on their operating time during the day) should be drawn up to reduce ASPP cost. In addition, it is necessary to exclude the simultaneous operation of high power consumers or a great number of low power consumers and to distribute load connections through time, so that the ASPP output capacity would tend to a minimum. For example, we assume that the microwave oven is connected to the network only after the electric kettle has been switched-off (No. 1 and No. 2, Table 1). Moreover, they should be connected to one AVI having one socket in order to provide an in-series consumer connection and to reduce ASPP cost.

When scheduling a load variation, it appears impossible to determine with precision the intervals for switching on loads with floating operating intervals (refrigerator, Table 1), so they may be assumed permanent for the sake of simplicity.

Considering the above mentioned factors, a schedule of the load variation per day may be set up as a table (Table 2). The total capacity of loads at the allocated time intervals may be calculated by the following formula:

Table 1. Total energy consumption per day.

\begin{tabular}{|c|c|c|c|c|c|}
\hline No. & Load & $\begin{array}{l}\text { Voltage, } \\
\text { capacity }\end{array}$ & $\begin{array}{c}\text { Capacity of } \\
\text { the main bus, } \mathrm{W}\end{array}$ & $\begin{array}{c}\text { Operating time, } \\
\text { hours per day }\end{array}$ & $\begin{array}{c}\text { Power } \\
\text { consumption }\end{array}$ \\
\hline 1. & Electric kettle, AVI & $\begin{array}{l}\sim 220 \mathrm{~V}, \\
1000 \mathrm{~W}\end{array}$ & 1250 & 0.25 & 312.5 \\
\hline 2. & Microwave oven, AVI & $\begin{array}{l}\sim 220 \mathrm{~V}, \\
1200 \mathrm{~W}\end{array}$ & 1500 & 0.25 & 375 \\
\hline 3. & Refrigerator, AVI & $\begin{array}{c}\sim 220 \mathrm{~V}, \\
250 \mathrm{~W}\end{array}$ & 312.5 & 12 & 3750 \\
\hline 4. & TV, AVI & $\begin{array}{c}\sim 220 \mathrm{~V}, \\
150 \mathrm{~W}\end{array}$ & 187.5 & 4 & 750 \\
\hline 5. & Hall lighting & $\begin{array}{l}=24 \mathrm{~V} \\
100 \mathrm{~W}\end{array}$ & 100 & 4 & 400 \\
\hline 6. & Kitchen and toilet lighting & $\begin{array}{l}=12 \mathrm{~V} \\
50 \mathrm{~W}\end{array}$ & 50 & 5 & 250 \\
\hline 7. & $\begin{array}{l}\text { Consumer } N 1, \mathrm{DC} / \mathrm{DC} \\
\text { converter }\end{array}$ & $\begin{array}{l}=48 \mathrm{~V} \\
120 \mathrm{~W}\end{array}$ & 150 & 5 & 750 \\
\hline 8. & $\begin{array}{l}\text { Consumer } N 2, \mathrm{DC} / \mathrm{DC} \\
\text { converter }\end{array}$ & $\begin{array}{l}=12 \mathrm{~V}, \\
90 \mathrm{~W}\end{array}$ & 112.5 & 3 & 337.5 \\
\hline & Total & & 3662.5 & & 6925 \\
\hline
\end{tabular}




$$
P_{l, j}=\sum_{i=1}^{N} P_{c, i}
$$

Here, $N$ is the number of consumers connected to the network at the $j$-th time interval.

At starting time, the electrical appliances, such as a refrigerator, pumps, an electric drill and a number of others, may consume power 5-6 times higher than the rated one. The great number of such high power consumers may result in an increase in the output capacity along with an increase in ASPP cost. In this case, it would be advisable to exclude the simultaneous connection of these electrical appliances as well as to provide the starting power from batteries.

During the daytime, the solar panel charges the battery and supply power to consumers. The daytime interval may be assumed as follows: $\Delta t_{d t}=14$ hours (6:00 - 20:00) in summer and $\Delta t_{d t}=8$ hours (8:00 16:00) in winter. Then the ASPP output capacity may be defined as the maximum load capacity per the interval of summer daytime according to the following formula:

$$
P_{l}=\max \left\{P_{l, j}\right\}, \quad \forall j \in \overline{1, M} .
$$

Here, $M$ stands for the number of allocated time intervals included in the summer daytime interval.

According to Table 2, the ASPP output capacity is $P_{l}=1,862.5 \mathrm{~W}$. This value would be used for calculating the ASPP solar panel capacity.

The above method for calculating the ASPP output capacity considers the variation of load capacities in time, being a general case. In a particular case, ASPP load would not change, i.e. it is constant. Such consumers include cellular stations, rapid power supply systems for power stations and substations, traffic lights, etc. In this case, the ASPP output capacity should correspond to the total load capacity.

\subsection{Stage 2: Calculating the ASPP Battery Capacity}

At night, the energy stored in ASPP battery is consumed by the load. The energy (energy intensity) of a battery may be defined as the product of its capacity into the rated voltage. Capacity shows the battery potential, i.e. the time during which it would be able to feed the load being fully charged. Capacity is measured in amperehours. As the discharge progresses, a drop of voltage and energy intensity occurs. Capacity consumption $\Delta C$ of ASPP rechargeable battery during powering the load $\Delta t_{n t}$ may be defined as follows:

$$
\Delta C=\frac{P_{l}}{U_{l}} \Delta t_{n t}=\frac{P_{l}}{U_{l}}\left(24-\Delta t_{d t}\right) .
$$

Here, $P_{l}$ is rated load capacity; $U_{l}$ is rated load voltage; $\Delta t_{n t}$ is night time interval $\left(\Delta t_{n t}=10\right.$ hours in summer, and $\Delta t_{n t}=16$ hours in winter); $\Delta t_{d t}$ is day time interval.

Deep discharge can damage a battery. Therefore, battery manufacturers set the final discharge voltage, at which the battery should be disconnected from the load and charged. To obtain a long lifespan of the battery, it should not be discharged by more than $70-80 \%$. The discharge level of ASPP battery may be written as follows:

$$
S_{d}=\frac{C_{l}-C_{\min }}{C_{l}} 100 \%=\frac{\Delta C}{C_{l}} 100 \% .
$$

The expression for determining the required capacity of ASPP battery could be obtained by expressing capacity $C_{l}$ from (5) with allowance for (4) in the following way:

\begin{tabular}{|c|c|c|c|c|c|c|c|c|c|c|c|c|c|c|}
\hline \multirow[b]{2}{*}{ No. } & \multirow[b]{2}{*}{ Load } & \multicolumn{13}{|c|}{ Capacities of loads at time intervals, $\mathrm{W}$} \\
\hline & & 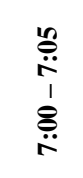 & 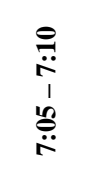 & $\begin{array}{l}\stackrel{8}{0} \\
\dot{0} \\
1 \\
\stackrel{\ddot{n}}{\ddot{n}}\end{array}$ & 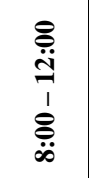 & 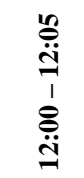 & 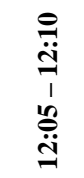 & 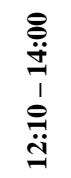 & 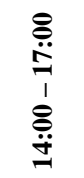 & 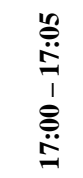 & 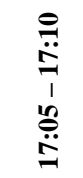 & 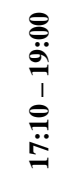 & $\begin{array}{l}8 \\
\ddot{\ddot{\nu}} \\
\text { ஸे } \\
1 \\
o \\
\ddot{g}\end{array}$ & 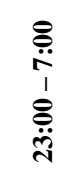 \\
\hline 1. & $\begin{array}{l}\text { Electric kettle, } \\
\text { AVI }\end{array}$ & 1250 & & & & 1250 & & & & 1250 & & & & \\
\hline 2. & $\begin{array}{l}\text { Microwave oven, } \\
\text { AVI }\end{array}$ & & 1500 & & & & 1500 & & & & 1500 & & & \\
\hline 3. & Refrigerator, AVI & \multicolumn{3}{|c|}{312.5} & 312.5 & \multicolumn{3}{|c|}{312.5} & 312.5 & \multicolumn{3}{|c|}{312.5} & 312.5 & 312.5 \\
\hline 4. & TV, AVI & & & & & & 18.5 & \\
\hline 5. & Hall lighting & & & & & & & & & & & & 100 & \\
\hline 6. & $\begin{array}{l}\text { Kitchen and toilet } \\
\text { lighting }\end{array}$ & \multicolumn{3}{|c|}{50} & & \multicolumn{3}{|c|}{50} & & \multicolumn{3}{|c|}{50} & & \\
\hline 7. & $\begin{array}{l}\text { Consumer N1, } \\
\text { DC/DC converter }\end{array}$ & & & 150 & & & & 150 & & & & 150 & & \\
\hline \multirow[t]{2}{*}{8.} & $\begin{array}{l}\text { Consumer N2, } \\
\text { DC/DC converter }\end{array}$ & & & & & & & & 112,5 & & & & & \\
\hline & Total & 1612.5 & 1862.5 & 512.5 & 312.5 & 1612.5 & 1862.5 & 512.5 & 425 & 1612.5 & 1862.5 & 512.5 & 600 & 312.5 \\
\hline
\end{tabular}

$$
C_{l}=\frac{100}{S_{d}} \frac{P_{l}}{U_{l}} \Delta t_{n t}
$$

Table 2. Schedule of the load variation per day. 
Equation (6) allows easily calculating the required ASPP battery capacity at constant load. Winter time is the most severe operation condition for ASPP batteries, so the value $\Delta t_{n t}=16$ hours and the degree of the battery discharge $S_{d}=70 \%$ is assumed when calculating by formula (6).

The higher the ASPP output voltage, the lower the capacity, the discharge current $I_{d}=P_{l} / U_{l}$ and the cost of the battery is. For stationary (industrial) lead-acid batteries, the maximum discharge current is limited to a value ranging from 5 to 25 battery capacities expressed numerically in amperes. The lower ASPP current, the lower the ohmic power loss, the higher the efficiency and, consequently, the lower the cost of the solar power plant is. Hence, it may be advantageous to have high voltage electrical systems. Moreover, the higher the power plant capacity, the greater the gain of the high-voltage system in comparison with the low-voltage one is.

In the past, almost all photovoltaic systems used a constant voltage of $12 \mathrm{~V}$, so $12 \mathrm{~V}$-devices powered directly from the battery were widely used. With the development of efficient and reliable inverters, the voltage of 24, $48 \mathrm{~V}$ and higher has been used in ASPP more often. Thus, autonomous solar power plants producing and consuming less than $1,000-1,500 \mathrm{~W} \cdot \mathrm{h}$ per day could be best combined with a voltage of $12 \mathrm{~V}$. ASPP producing $1,000-3,000 \mathrm{~W} \cdot \mathrm{h}$ per day usually use $24 \mathrm{~V}$, while ASPP producing more than $3,000 \mathrm{~W} \cdot \mathrm{h}$ per day use $48 \mathrm{~V}$ and more.

The system voltage may be a rather significant factor effecting the parameters of the inverter, controls, charger and wiring. Been once installed, these components are rather difficult to be replaced with. Some of them, such as photovoltaic modules, can be switched from $12 \mathrm{~V}$ to a higher voltage, while the others including inverter, wiring, and controls are designed for a specific voltage and can operate within it only.

ASPP battery with capacity $C_{l}$ may be assembled from separate commercially manufactured low capacity batteries by connecting them in series and in parallel. An in-series connection of separate batteries is used to increase the voltage, while the capacity of the battery branch corresponds to the separate battery capacity. The resulting battery connected in parallel has the same voltage as a separate battery, while the capacity of this battery is equal to the sum of capacities of its separate batteries.

The energy intensity of ASPP battery may be calculated as follows:

$$
W=C_{l} U_{l} .
$$

The number of in-series connected separate batteries in a branch may be written as follows:

$$
n=U_{l} / U_{b} .
$$

Here, $U_{b}$ is the voltage of a separate battery.

The number of parallel branches in ASPP battery may be written as follows:

$$
m=C_{l} / C_{b} .
$$

Here, $C_{b}$ is the capacity of a separate battery.

Then, the total number of separate batteries in ASPP battery would be written in the following way:

$$
N=n \cdot m .
$$

The ratio for determining the total number of separate batteries in ASPP battery could be obtained by substituting equations (6)-(9) in (10) as follows:

$$
N=\frac{100}{S_{d}} \frac{P_{l}}{W_{b}} \Delta t_{n t},
$$

Here, $W_{b}=C_{b} U_{b}$ is the energy intensity of a separate battery. The higher energy consumption or capacity at a given battery voltage is, the less separate batteries in ASPP battery pack would be required. The expression for determining the ASPP battery voltage may be written by selecting a battery of a given capacity from equations (6) and (9) in the following way:

$$
U_{l}=\frac{100}{S_{d}} \frac{P_{l}}{m C_{b}} \Delta t_{n t} .
$$

In general case, ASPP load is non-constant, i.e. it changes in time. According to the Table 2, a load variation in the night time interval (16:00 - 8:00) could be approximated by the graph shown in Fig. 1. For the graph simplicity, the load is represented by two values $P_{l 1}=1,863 \mathrm{~W}$ and $P_{l 2}=600 \mathrm{~W}$ at five time intervals. Combining the time intervals shown in the graph (Fig. 1) with the same load values, a two-step graph of load variation (Fig. 2,a) could be obtained. Time intervals $\Delta t_{1}$ and $\Delta t_{2}$ defined as the sum of the time intervals with the load $P_{l 1}$ and $P_{l 2}$ are equal to $\Delta t_{1}=1 / 3 \mathrm{~h}$ and $\Delta t_{1}=$ $15 \cdot 2 / 3 \mathrm{~h}$, respectively.

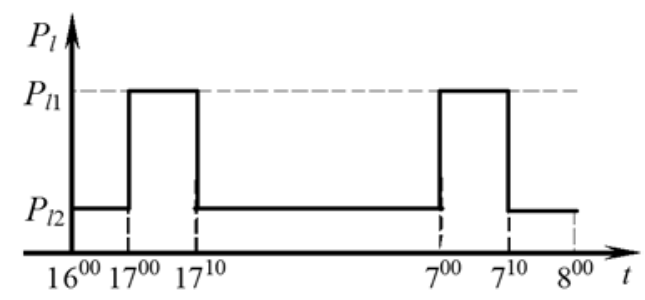

Fig. 1. Simplified graph of load variation.

The graph of the ASPP battery capacity variation at the two-step load is shown in Fig. 2, $b$. The battery capacity consumption in the first time interval may be defined as follows:

$$
\Delta C_{1}=\frac{P_{11}}{U_{l}} \Delta t_{1},
$$

while in the second time interval it could be written in the following way:

$$
\Delta C_{2}=\frac{P_{12}}{U_{l}} \Delta t_{2} .
$$



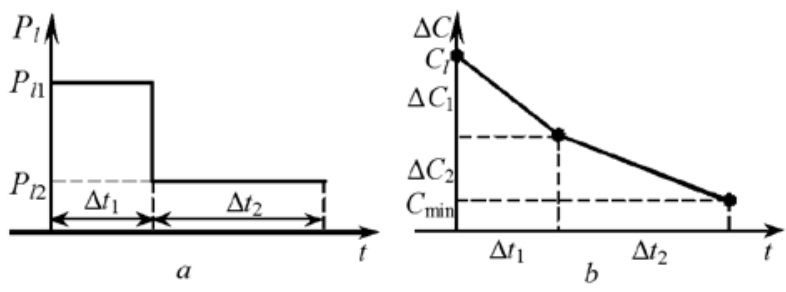

Fig. 2. Graphs of the load (a) and battery capacity (b) variation.

Considering that $\Delta C=\Delta C_{1}+\Delta C_{2}$, the expression for determining the ASPP required battery capacity could be obtained from (5), (13) and (14) as follows:

$$
C_{l}=\frac{100}{S_{d} U_{l}}\left(P_{11} \Delta t_{1}+P_{12} \Delta t_{2}\right) .
$$

Obviously, the calculation by equation (15) gives an overestimate of the required battery capacity. To determine the required capacity more accurate, the change in the load curve over the night time interval of the day should be considered as precisely as possible.

\subsection{Stage 3: Calculating the ASPP Charger Capacity}

Charging the battery is the reverse process of discharging [13-14]; during charging, the battery stores energy powered by an external power source or a solar panel. After fully charged, the battery accumulates a charge equal to the capacity of the battery.

There are two methods of battery charging: charging at constant current or charging at constant voltage [1517]. Both of these methods are equivalent in terms of their effect on the battery lifespan.

Charging at constant current [18-19] is performed by current having the value equal to $10 \%$ of the rated capacity at a 20-hour discharge mode. For most stationary lead-acid batteries, the current value is written on their case. The maximum charging current is between 0.2 and 0.3 battery capacities. A regulating device would be required to maintain the constancy of the current throughout the entire charging process. The disadvantage of this charging method is the need for constant monitoring and regulating the charging current as well as abundant gas emission at the end of charging. To reduce gas emission and increase the degree of the battery charge, it may be advisable to step-down the current as the charging voltage increases. When the voltage reaches $14.4 \mathrm{~V}$, the charging current is halved, and the charging process proceeds at this current until gas emission begins. When charging batteries having no holes for water refilling, it would be reasonable to halve the current again when the charging voltage is increased to $15 \mathrm{~V}$. The battery is considered fully charged when the current and voltage remain unchanged for one or two hours during charging. For modern maintenance-free batteries, this condition occurs at a voltage of $16.3-16.4 \mathrm{~V}$.

The electrolyte temperature increases during charging, so it is necessary to control its value, especially by the end of charging. If electrolyte density differs from the norm by the end of charging, then it would be necessary to make an adjustment by adding distilled water when the density is above the norm or by adding a sulfuric acid solution with a density of 1.4 $\mathrm{g} / \mathrm{cm}^{3}$ when it is below the norm.

When charging at constant voltage [20], the degree of the battery charge at the end of charging depends directly on the value of charging voltage. For example, a fully discharged 12-volt battery will be charged by $75-85 \%$ in 24 hours of continuous charging at $14.4 \mathrm{~V}$. And, it would be charged by $85-90 \%$ and $95-97 \%$ at $15 \mathrm{~V}$ and at $16 \mathrm{~V}$, respectively. A discharged battery could be fully charged in 20-24 hours at the charger voltage of 16.3-16.4V. At the first moment the charger is switched on, the current could reach $40-50 \mathrm{~A}$ or higher. Hence, the charger must be equipped with circuit solutions limiting the maximum charge current.

The accelerated combined charging method that involves two stages should be used for full battery charging in reduced time. At the first stage, charging is performed by direct current until the voltage reaches $14.5 \mathrm{~V}$, and at the second stage the process runs at a constant voltage of $13.8 \mathrm{~V}$. This accelerated charging method is called sometimes IU-charging (currentvoltage). The method allows fully charging the lead-acid battery in about six hours at initial charging current of $20 \%$ of the capacity. Accelerated charging is used more frequently in the case the batteries are operated in a cyclic mode, i.e. in ASPP.

In view of the foregoing, charging a 12 -volt battery $\left(U_{b}=12 \mathrm{~V}\right)$ may require maximum charging current $I_{\max . c h}=0.2 \cdot \mathrm{C} / 1 \mathrm{~h}$ and the charger maximum output voltage $U_{\text {max.ch }}=16.5 \mathrm{~V}$. In general, ASPP battery consists of $n$ separate batteries connected in-series. In this case, the charger output capacity may be written as follows:

$$
P_{c h}=n I_{\text {max.ch }} U_{\text {max.ch }}
$$

Charging lead-acid batteries connected in-series may be dangerous. When the in-series connected batteries with different capacities are charged, their parameters (energy consumption, voltage) become more and more divergent, i.e. "they scatter". Therefore, charging of separate batteries from separate chargers is actually wide-used. Separate charging requires $n$ charging devices having $n$ times less capacity.

\subsection{Stage 4: Calculating the ASPP Main Tire Capacity}

All electricity consumers as well as ASPP battery charger are powered via the main bus. The main bus throughput capacity should be defined to select the right cross-section of the main tire and determine the capacity of ASPP solar panels. The throughput capacity of the ASPP main bus may be found out as the sum of load capacities and the battery charge:

$$
P_{m b}=P_{l}+P_{c h} / \eta_{2} .
$$

Here, $P_{l}$ is ASPP load capacity; $P_{c h}$ is ASPP charger capacity; $\eta_{2}$ is ASPP charger efficiency. 


\subsection{Stage 5: Calculating the ASPP Solar Panel Capacity}

Calculation of the ASPP solar panel capacity is required for their correct selection and providing the necessary amount of electricity for an autonomous solar power plant. The required capacity of the solar panel may be determined by the following ratio:

$$
P_{s p}=P_{m b} / \eta_{1}=P_{l} / \eta_{1}+P_{c h} /\left(\eta_{1} \eta_{2}\right) .
$$

Here, $\eta_{1}$ is the buck DC/DC pulse converter efficiency.

The amount of electricity produced by a solar panel depends on weather conditions. Considering this factor requires determining the amount of solar energy that can be counted on in a given area. Generally, this data can be obtained from local solar panel supplier or at weather station. The following two factors should be taken into account here: average annual solar radiation along with its monthly averages under the worst weather conditions.

The first factor allows calculating the photovoltaic system in accordance with average annual solar radiation (i.e. there will be more energy than required in some months with less in others). When selecting the second factor, there would always be at least enough energy to meet needs, provided extremely long periods of bad weather are excluded.

Then, the rated capacity of a photovoltaic module can be calculated.

The solar radiation value for the period under consideration should be taken from Tables and divided by 1,000 to obtain the so-called 'peak hours', i.e. the conditional time during which the sun shines with some kind of intensity of $1,000 \mathrm{~W} / \mathrm{m}^{2}$.

The module with $P_{W}$ capacity may produce the following amount of energy during the selected period:

$$
W=k \cdot E \cdot P_{W} / 1,000 .
$$

Here, $E$ is insolation for the selected period; $k$ is a coefficient equal to 0.5 and 0.7 in summertime and wintertime, respectively. It makes allowances for the loss of the solar panel capacity when heated in the sun as well as takes into account the inclined incidence of sunrays on the module surface during the day. The difference between its winter and summer values is due to less heating of components in wintertime.

Based on the total energy consumption and the above formula, the total capacity of all modules could be easily calculated, and the number of modules would be obtained by simply dividing the resulting value by the capacity of one module.

The use of photovoltaic modules with different capacities may allow building a solar panel with the required installed capacity. There would be two possible options here: either insufficient or excessive capacity of solar panels. In the first case, the solar panel wouldn't be able to meet total energy needs. In the second case, the excess electric energy occurs.

\subsection{Stage 6: Calculating the ASPP efficiency}

The ASPP performance evaluation is determined by the efficiency. The ASPP efficiency could be calculated as follows:

$$
\eta=\frac{P_{1}}{P_{s p}}=\frac{P_{1} \eta_{1} \eta_{2}}{P_{l} \eta_{2}+P_{c h}} .
$$

\subsection{Stage 7: Selecting AVI for ASPP}

When selecting the inverter, total load of the devices connected to the inverter should be calculated, and the resulting value should be increased at least by $30 \%$. The selected inverter allows starting electrical appliances (such as the compressor refrigerator, pumps, etc.) with starting capacities 3-4 times higher than the rated one.

In the case under consideration, AVI consistently powers the electric kettle and the microwave oven via one outlet. In addition, the microwave oven capacity is higher than that of the electric kettle. Thus, the inverter capacity amounts to $1,950 \mathrm{~W}$ and is determined by the $30 \%$ increase of the microwave oven capacity recalculated for the main bus.

\section{Results and Discussion}

Computers allow significantly reducing the time for designing solar power plants. The current stage of using the computers for designing solar power plants may be characterized by the widespread involvement of universal software systems with a rich set of cell libraries allowing significantly enhancing the designing efficiency as well as reducing costs for prototyping and full-scale experiment.

Hence, the exact mathematical models along with specific software systems for expediting the designing should be developed to increase the designing efficiency of solar power plants. The computer-based designing of solar power plants isn't fully covered in the available literature, so the development of programs for calculating the capacity of solar power plants and their components becomes increasingly relevant.

The study aims at developing the software for calculating the capacity of ASPP and its components in LabVIEW environment. Based on ratios obtained above, the program for calculating ASPP capacity using the graphic programming language has been developed in LabVIEW environment. The block-modular programming principle used by LabVIEW allows autonomously debugging the operation of modules - the solar power plant components - as well as expediting the programming process.

The program developed by the authors is presented as two virtual instruments (calculators) operating independently of one other. The first calculator allows automatically recalculating the load capacity on the main power bus of the power plant as well as determining the energy consumption of loads per day.

The front panel of the first calculator is shown in Fig. 3. The instrument contains windows for setting load capacities 
as well as the efficiency of inverters and pulse converters of constant voltage and operating times of electrical appliances. Calculation results are displayed via the windows of load capacities on the main bus and power consumption per day. In addition, the windows of total load capacities and energy consumption are placed on the front panel of the instrument. The calculator block diagram has been developed on the basis of the "Formula" node (Fig. 4), and it has a fairly low laboriousness and high visibility. The program exhibits low computing time consumption in calculations.

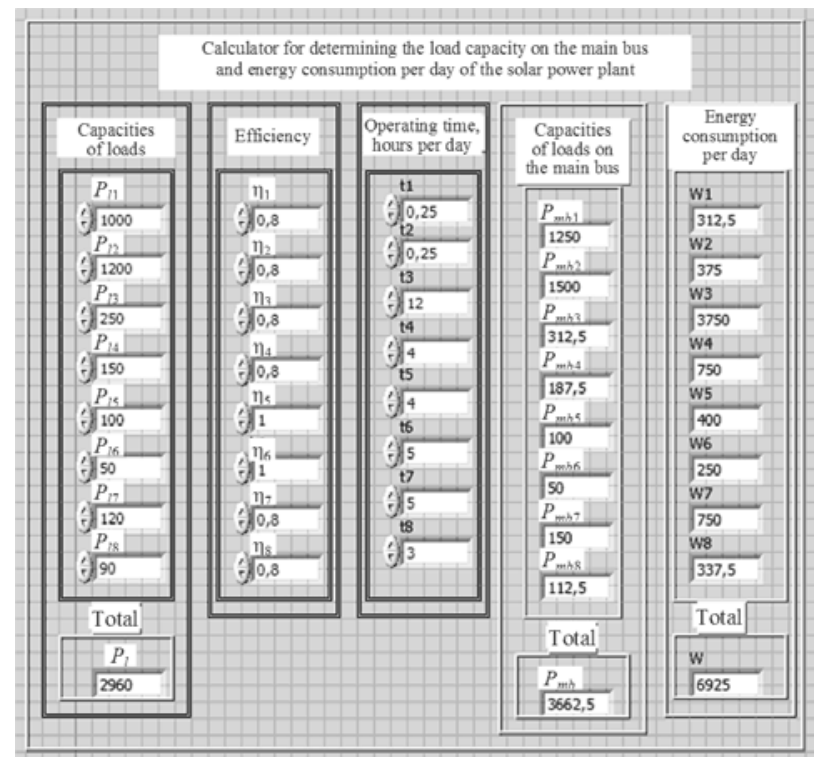

Fig. 3. Front panel of the first calculator.

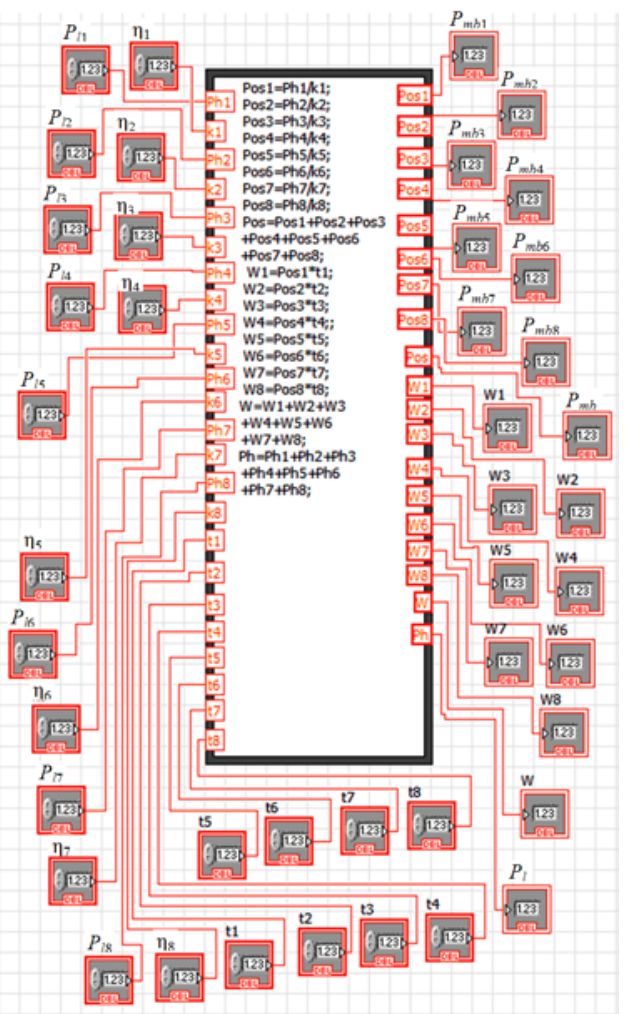

Fig. 4. Block diagram of the first calculator operation algorithm.
The second virtual instrument (calculator) is used to determine the required capacity of the solar power plant battery and the number of separate batteries as well as to determine the capacity of the charger, inverters, main power bus and solar modules along with the solar power plant efficiency.

The front panel of the second calculator and the structural diagram are shown in Fig. 5 and 6, respectively. The front panel is provided with windows for setting maximum load capacities and their switchingon intervals, the degree of the battery discharge and voltage, the output voltage of the solar power station as well as with windows showing calculated values of the power plant parameters. The structural diagram of the second calculator has been also developed on the basis of the "Formula" node. The calculator is characterized by low computing time consumption in calculations.

\begin{tabular}{|c|c|c|c|c|c|}
\hline \multirow{5}{*}[\begin{array}{c}{\text{Capacities}}\\
{\text{ofloads}}\\
{P_{n1}}\\
{6\sqrt{1363}}\\
{P_{h2}}\\
{6000}\end{array}]{} & \multirow[b]{2}{*}{$\begin{array}{l}\text { Operating } \\
\text { time }\end{array}$} & \multicolumn{3}{|c|}{$\begin{array}{l}\text { Calculator for determining the capacity } \\
\text { of the solar power plant and its elements }\end{array}$} & \multirow{2}{*}{$\begin{array}{c}\text { Capacity of } \\
\text { charger } \\
P_{c h} \\
\mid 1300,54\end{array}$} \\
\hline & & $\begin{array}{l}\text { Discharge } \\
\text { level }\end{array}$ & $\begin{array}{l}\text { Required } \\
\text { capacity of }\end{array}$ & $\begin{array}{l}\text { Count } \\
\text { of series }\end{array}$ & \\
\hline & (5) 0.3333 & spotit & $C_{1} \sqrt{394,103}$ & batteries & Capacity of \\
\hline & & $9 \sqrt{70}$ & Eneroy & $n \longdiv { 2 }$ & main bus \\
\hline & & & intensity & Count & $P_{m 0} \sqrt{3438,68}$ \\
\hline Voltages & & $\begin{array}{l}\text { Capacity of } \\
\text { one battery }\end{array}$ & $\frac{W}{99458,48}$ & $\begin{array}{c}\text { of parallel } \\
\text { branches }\end{array}$ & $\begin{array}{l}\text { Capacity of the } \\
\text { solar panel }\end{array}$ \\
\hline & Efficiencies & $C_{b}$ & Current & $m \sqrt[3,94103]{\text { Full }}$ & $P _ { s p } \longdiv { 4 3 5 0 , 8 5 }$ \\
\hline ) ${ }_{24}^{24}$ & 910,8 & & $\begin{array}{l}\text { of charger } \\
I_{\max , f k}\end{array}$ & count of & Efficiency of \\
\hline 6) 12 & 60.8 & & & $N 77,82207$ & \\
\hline
\end{tabular}

Fig. 5. Front panel of the second calculator.

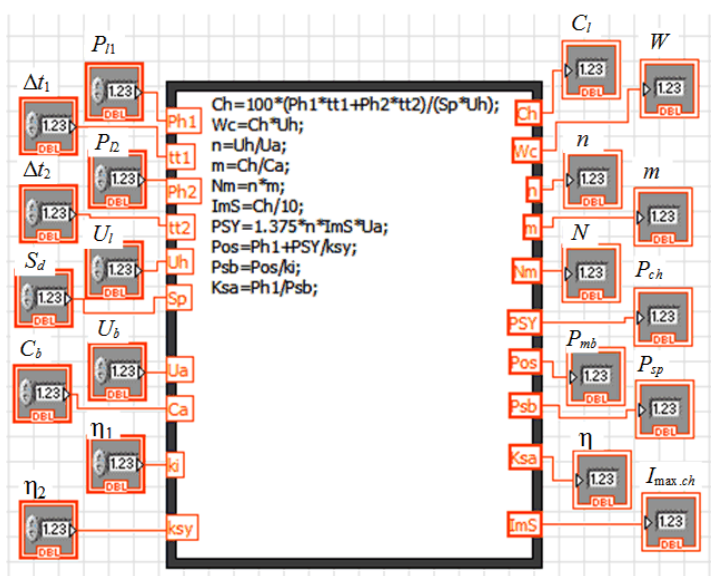

Fig. 6. Block diagram of the second calculator operation algorithm.

\section{Conclusions}

1. A method for calculating the capacity of autonomous solar power plants and their components allowing taking into account the load variation during the day has been developed.

2. The required battery capacity can be determined with precision by taking into account variations in the load schedule overnight.

3. The expression for determining the required ASPP battery capacity can be easily generalized for any number of changes in the steps of the load graph. 
4. The method for calculating ASPP capacity allows excluding the unjustified overestimation of the power plant component capacities and the increase in ASPP cost.

5. The calculators have a fairly high visibility, ease of use, small amount of the required memory and low computing time consumption in calculations.

6. The first calculator allows recalculating the load capacity on the main power supply bus of the power plant as well as determining the energy consumption of loads per day, while the second calculator serves to determine the required capacity and number of batteries, the capacity of the charger, inverters, main power bus and solar modules along with the solar power plant efficiency.

\section{References}

1. R.A. Diantari, I. Pujotomo 2016 Calculation of electrical energy with solar power plant design Proc. of 2016 Int. Seminar on Intelligent Technology and Its Applications (ISITIA) 443-446

2. T. Nakayama, K. Mineno, N. Thi, H. Thu, M. Ishida 2016 A method for capacity designing of a photovoltaic power generation with a battery using annual total amount of solar radiation analysis model Proc. of 2016 51st Int. Universities Power Engineering Conf. (UPEC) 1-6

3. J. Wingens, G. Krost, D. Ostermann, U. Damm, J. Hess 2008 Application of photo-electrochemical hydrogen production for autonomous solar based electricity supply Proc. of 2008 Third Int. Conf. on Electric Utility Deregulation and Restructuring and Power Technologies 2470-2475

4. S.A. Arefifar, F. Paz, M. Ordonez, IEEE Journal of Emerging and Selected Topics in Power Electronics 5(2), 638-650 (2017)

5. S.V. Mitrofanov, D.K. Baykasenov, M.A. Suleev 2018 Simulation Model of Autonomous Solar Power Plant with Dual-Axis Solar Tracker Proc. of 2018 Int. Ural Conf. on Green Energy (UralCon) 90-96

6. S.V. Mitrofanov, D.K. Baykasenov, M.A. Suleev 2018 Complex System of Protection of Autonomous Solar Power Plant with Sun-Tracking System Proc. of 2018 Int. Conf. on Industrial Engineering, Applications and Manufacturing (ICIEAM) 1-5

7. S.A. Grigoriev, A.S. Grigoriev, N.V. Kuleshov, D.A. Melnik, V.K. Dragunov 2018 Standalone solar-wind-electrochemical energy systems for northern territories Proc. of 2018 Int. Conf. "Renewable Energies, Power Systems \& Green Inclusive Economy” (REPS-GIE) 1-5

8. B.V. Lukutin, E.B. Shandarova, I.L. Fuks 2016 Energy efficiency of photovoltaic power plants in stand-alone power supply systems Proc. of 2016 2nd Int. Conf. on Industrial Engineering, Applications and Manufacturing (ICIEAM) 1-5

9. B. Dhivya, K. Malarvizhi 2017 Design of hybrid concentrated solar and wind power plant for the autonomy of islands Proc. of 2017 Int. Conf. on Inventive Systems and Control (ICISC) 1-6

10. S.K. Tiwari, B. Singh, P. Kr. Goel, IEEE Transactions on Industry Applications 54(2), 11191127 (2018)

11. P. Thounthong, S. Sikkabut, P. Mungporn, L. Piegari, B. Nahid-Mobarakeh, S. Pierfederici, B. Davat, IEEE Transactions on Industry Applications 51(4), 2717-2725 (2015)

12. A. Jahangir, S. Mishra 2018 Autonomous Battery Storage Energy System Control of PV-Wind Based DC Microgrid Proc. of 2018 2nd Int. Conf. on Power, Energy and Environment: Towards Smart Technology (ICEPE) 1-6

13. D.N. Craig, J.W. Hamer, Transactions of the American Institute of Electrical Engineers, Part II: Applications and Industry 73(1), 22-34 (1954)

14. W. Song, Y. Chen, Y. Zhang, A. Wen, C. Wei, Electronics Letters 55(7), 402-404 (2019)

15. V.-B. Vu, D.-H. Tran, W. Choi, IEEE Transactions on Power Electronics 33(9), 7398-7410 (2018)

16. M. Li, G.-R. Zhu, J.-H. Lu, W.-J. Li, B. Li, B.-Y. Luo 2018 A Three-bridge Topology for Constant Current and Constant Voltage Output in IPT System Proc. of 2018 IEEE Int. Power Electronics and Application Conf. and Exposition (PEAC) 1-5

17. X. Qu, H. Han, S.-C. Wong, C.K. Tse, W. Chen, IEEE Transactions on Power Electronics 30(11), 6329-6337 (2015)

18. A.B. Khan, W. Choi, IEEE Transactions on Energy Conversion 33(3), 1132-1140 (2018)

19. J. Jiang, L. Pan, L. Che 2017 Research on control strategy of constant current charging power supply Proc. of 2017 29th Chinese Control And Decision Conf. (CCDC) 4000-4005

20. L. Patnaik, A.V.J.S. Praneeth, S.S. Williamson, IEEE Transactions on Industrial Electronics 66(2), 1059-1067 (2019) 